\title{
The umbilical cord, preeclampsia and the VEGF family
}

This article was published in the following Dove Press journal:

International Journal of Women's Health

\author{
Mercedes Olaya-C' \\ Marta Garrido ${ }^{2}$ \\ Javier Hernandez-Losa ${ }^{2-4}$ \\ Marta Sesé ${ }^{2-4}$ \\ Paola Ayala-Ramirez ${ }^{5}$ \\ Rosa Somoza ${ }^{2-4}$ \\ Magda Jimena Vargas ${ }^{6}$ \\ Santiago Ramón y Cajal ${ }^{2-4}$ \\ 'Department of Pathology, Institute \\ of Human Genetics, The Medical \\ School, Pontificia Universidad \\ Javeriana - Hospital Universitario San \\ Ignacio, Bogota, Colombia; ${ }^{2}$ Pathology \\ Department, Vall d'Hebron Hospital, \\ Barcelona, Spain; ${ }^{3}$ Translational \\ Molecular Pathology, Vall d'Hebron \\ Research Institute (VHIR), Universitat \\ Autònoma de Barcelona, Barcelona, \\ Spain; ${ }^{4}$ Spanish Biomedical Research \\ Network Center in Oncology \\ (CIBERONC), Barcelona, Spain; \\ ${ }^{5}$ Institute of Human Genetics, \\ The Medical School, Pontificia \\ Universidad Javeriana, Bogota, \\ Colombia; ' Department of Pathology, \\ The Medical School, Pontificia \\ Universidad Javeriana - Hospital \\ Universitario San Ignacio, Bogota, \\ Colombia
}

Correspondence: Mercedes Olaya-C Departamento de Patología, Facultad de Medicina, Pontificia Universidad Javeriana - Hospital Universitario San Ignacio, Carrera 7, 40-62 Bogota, Colombia

Tel +57 I594 6I6I ext 2440

Email olaya.m@javeriana.edu.co
Introduction: The VEGF family has been identified as abnormal in preeclampsia (PE). Hypertensive disorders of pregnancy (HDP) are major contributors to maternal and neonatal morbidity and mortality worldwide; likewise, umbilical cord anatomical abnormalities (UCAA) are linked to poor neonatal outcomes. Based on the relationship described between PE and UCAA and the role of the VEGF family in PE, this study explored VEGF expression in placental and UC tissued from patients with PE and with UCAA.

Methods: We performed an observational, analytical study on placentas, comparing protein and mRNA expression in four groups: patients with PE, patients with UC abnormalities, patients with both, and patients with none of them. Using immunohistochemistry, we studied VEGF A, VEGF R1 (FLT1), MMP1, and PLGF. With quantitative reverse transcription polymerase chain reaction we described mRNA expression of PLGF, VEGF and $s F L T 1$, and $s F L T 1 / P L G F$ ratio.

Results: Forty newborns were included. Sixty-seven percent of mothers and $45 \%$ of newborns developed no complications. Immunohistochemistry was performed on UC and placental disc paraffin-embedded tissue; in the latter, the mRNA of the VEGF family was also measured. Statistically significant differences were observed among different expressions in both HDP and UCAA groups. Interestingly, the UCAA group exhibited lower levels of sFLT1 and VEGF-A in comparison with other groups, with significant $P$-value for sFLT1 $(P=0000.1)$.

Conclusion: The origin of UCAA abnormalities and their relation with HDP are still unknown. VEGF family alterations could be involved in both. This study provides the first approach related to molecules linked to UCAA.

Keywords: preeclampsia, umbilical cord, VEGF, sFLT1, PLGF, stillbirth

\section{Introduction}

The most prevalent hypertensive disorders of pregnancy (HDP) is the preeclampsia (PE), a syndrome that severely and frequently affects pregnancies: from $4 \%$ to $10.7 \%$ in a WHO Global Survey (24 countries). ${ }^{1-3}$ PE causes substantial maternal, fetal, and neonatal morbidity and mortality. The impact on maternal mortality is very high, around 2.8\% in the United Kingdom, 7.4\% in the United States, 26\% in Latin America and the Caribbean, 9\% in Africa and Asia, and 14\% globally in 2013., ${ }^{4,5}$ Furthermore, long-term maternal morbidity has been recognized as being related to renal and cardiovascular risks. $^{6-9}$ In newborns, its relation to intrauterine growth restriction and prematurity is well known, ${ }^{10}$ as well as to subsequent bronchopulmonary dysplasia, chronic lung disease, and neurodevelopmental delay. ${ }^{11}$ Stillbirths like a PE complication could rise at $30.2 \%$. $^{7,12}$ Future cardiovascular risk for the newborn caused by fetal programming has been also reported. . $^{3,11,13,14}$

As an important placental component, the umbilical cord (UC) has been found to be abnormal in its anatomical features in PE. ${ }^{15-18} \mathrm{UC}$ anatomical alterations are 
also linked to abnormal prognosis, principally death and neurodisabilities. ${ }^{19-21}$

We hypothesized about the common vascular origin of the placenta and also of the UC, and the alterations linking them, as well as about the abnormal performance of VEGF in HDP. PE is associated with distorted placental proteins that belong to the VEGF family, which have also been described as important during embryo development and implantation. ${ }^{22}$ These proteins are synthesized by the trophoblast and endometrium ${ }^{22}$ and secreted into the maternal blood stream; ${ }^{23}$ maternal levels of circulating derived proteins related to the vascular role (angiogenesis and maternal spiral artery remodeling) are deregulated in $\mathrm{PE},{ }^{24}$ specifically sFlt-1 (soluble fms-like tyrosine kinase 1) and PLGF (placental growth factor). In order to prevent complications and to prepare for the optimum care in these cases, some predictors are currently being developed; studies show that the sFlt-1:PLGF ratio is useful for predicting the short-term absence of PE in women in whom the disorder is suspected..$^{25,26}$ This study provides the first molecular family analysis, which can link two entities already statistically linked; it explores VEGF protein and mRNA expression in the placenta and compares PE and UC morphological alterations with those in normal gestations, exploring, for the first time, this molecular nexus between both vascular abnormalities of pregnancy.

\section{Methods}

\section{Samples}

We performed an observational, analytical study on placental and UC tissue. Previously, patients had provided written informed consent for the use of their tissues for further investigations. We designed four groups: HDP, UCAA; HDP plus UCAA, and normal gestations. The Institutional Research and Ethics Committee of the Faculty of Medicine, Pontificia Universidad Javeriana - Hospital Universitario San Ignacio approved this study. Each group included ten participants. Maternal and fetal clinical records were reviewed. In the first group, the HDP group, hypertension during the gestation was classified according to American College of Obstetricians and Gynecologists (2013) guidelines. ${ }^{27}$ The UCs in this group were found to be completely normal. The UCAA group encompassed placentas with UC alterations, including abnormal length (short or long, based on to tables available in the literature); ${ }^{28}$ abnormal insertion (velamentous, furcate, marginal and paramarginal [inserted within $1 \mathrm{~cm}$ from the placenta]); and abnormal coiled cords (coiling index $>0.3$ or $<0.07$ turns per $\mathrm{cm}$ ). Most cords had counterclockwise (also called a left twist), dextrorotatory (clockwise), and bidirectional coiling, all of which are related to complications. Also, the number of cord vessels (two, three, or more), the presence of entanglements (cord tangles in fetal body parts), and true UC knots were noted. In this group, mothers did not have HDP. The third group comprises women with HDP and any kind of UCAA. In the last group, mothers had neither HDP nor UCAA; furthermore, these mothers had had no previous ailments, nor had they developed any complications during pregnancy, and they had left the hospital in good health. Their newborns were within adequate weight standards; none suffered from malformations, chromosomal diseases, nor any other complications; and they left the hospital in good health.

\section{Immunohistochemistry}

By means of immunohistochemistry, VEGF-A (GTX102643), VEGF-R1 (FLT1) (GTX15294), MMP1 (GTX100534), and PLGF (GTX54606) were studied using GeneTex ${ }^{\circledR}$ paraffinembedded sections, which were rehydrated and incubated for 55 minutes at $20^{\circ} \mathrm{C}$ in methanol containing $10 \% \mathrm{H}_{2} \mathrm{O}_{2}$ to block endogenous peroxidase (EnVision ${ }^{\mathrm{TM}}$ FLEX + kit; Dako ${ }^{\circledR}$ ). Section pretreatment was carried out with the same kit in order to facilitate antigen retrieval and increase membrane permeability to antibodies; following this step, samples were then incubated with the primary antibody. Concentrations were: VEGF A (1:600), VEGF R1 (ready to use), MMP1 (1:500), and PLGF (1:150). Positive reaction was visualized by 3.3-diaminobenzidine peroxidation according to standard methods. Sections were counterstained with Harris's hematoxylin, dehydrated, coverslipped, and observed under an optical microscope. Positive and negative controls were performed and validated for each antibody. Two blinded perinatal pathologists evaluated the immunostaining, discriminating between spread $(0 \%,<30 \%, 30 \%-60 \%,>60 \%)$ and intensity. Intensity had four categories: not expressed, 0 ; weak intensity, 1 ; moderate intensity, 2 ; and strong intensity, 3 .

\section{RNA extraction and quantitative reverse transcription polymerase chain reaction (qRT-PCR)}

RNA extraction was made from the paraffin-imbibed tissue using the High Pure FFPET RNA Isolation Kit $\left(\right.$ Roche $^{\circledR}$ ), following manufacturer's recommendations. Briefly, $10 \mu \mathrm{m}$ thick section of formalin-fixed, paraffin-embedded tissue was taken from each placenta; after deparaffinazation of placenta samples, a RNA tissue lysis buffer, such as SDS 
and/or proteinase $\mathrm{K}$ working solution, was added. Tissue was incubated for 30 minutes at $+85^{\circ} \mathrm{C}$ while shaken. Proteinase $\mathrm{K}$ working solution was added again, incubated for 30 minutes at $+55^{\circ} \mathrm{C}$ while shaken at $600 \mathrm{rpm}$, thereby obtaining clear lysate. A RNA-binding buffer and ethanol were added, and samples were placed in several High Pure Collection Tubes. Following some centrifugation cycles and discarding flowthrough, a DNase working solution was added; the tissue was then completely solubilized. Yield of RNA was quantified with a Nanodrop 1000 spectrophotometer.

\section{cDNA synthesis}

Two hundred nanograms of RNA were reverse transcribed at $25^{\circ} \mathrm{C}$ for 10 minutes, and afterward, at $37^{\circ} \mathrm{C}$ for 120 minutes, finally at $85^{\circ} \mathrm{C}$ for 5 minutes, using an Applied Biosystem Kit (Thermo Fisher Scientific) in a thermocycler (Touchgene Gradient-Techner ${ }^{\circledR}$ ).

\section{Quantitative qPCR with SYBR green}

Specific primers for PLGF, VEGF, and sFLT1 genes and housekeeping $18 \mathrm{~S}$ gene were designed to amplify and quantify mRNA by real-time PCR, from Invitrogen ${ }^{\circledR}$ (Table 1). Two microliters of cDNA of each sample were included by triplicate using $10 \mathrm{pmol}$ of forward and reverse primers. Each PCR reaction included a negative control. The reaction was conducted in a final volume of $10 \mu \mathrm{L}$, and the qPCR was run on a 7500 Fast Real-Time PCR System (Applied Biosystems $\left.^{\circledR}\right)$. To quantify changes in gene expression, the comparative $\mathrm{Ct}$ ( $\Delta \Delta \mathrm{Ct}$ method) was used to calculate the relative fold change normalized to $18 \mathrm{~S}$.

\section{Statistics analysis}

Regarding statistical methodology, Friedman's chi-squared test, a one-way repeated variance measurement analysis, was used to evaluate differences in protein expression among the groups. To evaluate differences in mRNA levels, the nonparametric Kruskall-Wallis test was used. Statistical analysis was performed with Stata 14.2 (StataCorp. LP 2015; Stata Statistical Software: Release 14, College Station, TX, USA).

\section{Results \\ Population characteristics}

Forty cases were included. This cohort was designed with $50 \%$ of cases with HDP. There was no difference between genders in neonates. Maternal and paternal ages were alike in the consecutive cohorts. Primipaternity was present in $67.5 \%$ of gestations, only half were related with HDP (Table 2). Maternal age $\geq 30$ years showed significant association with HDP: $P=0.02 ; \mathrm{OR}=5.44 ; 95 \% \mathrm{CI}=1.4-21.05$. Twenty percent of all mothers presented chronic hypertension and this whole subgroup developed superimposed PE; this higher risk is known. ${ }^{29}$ Only $45 \%$ of the women began gestation with no pathological condition, $67 \%$ of mothers developed some gestational complication (Table 3 ), and $45 \%$ of newborns presented some complication (Table 3). Most frequent newborn complications were jaundice $(20 \%)$ and respiratory distress syndrome (17.5\%). Intrauterine growth restriction was observed in $7.5 \%$ (percentile $<10$ ), all of them in the HDP context. Maternal weight was abnormal in $80 \%$ of patients (35\% less than expected and $45 \%$ more than expected). This cohort was also designed with $50 \%$ of UC anatomical alterations; UC alterations are shown in Table 4. We only missed data for UC length, because complete UC length is not being routinely measure. This loss was random because there was no bias on the part of obstetricians, who selected neither newborns nor placentas. On the other hand, we did not observe more or different complications in the mother or in the newborn in the group without complete UC length. The group to

Table I Primers of PLGF, sFLTI, VEGF and I8S genes

\begin{tabular}{|c|c|c|c|}
\hline Gene & Direction & Primer sequence $\left(5^{\prime}-3^{\prime}\right)$ & Fragments size \\
\hline \multirow[t]{2}{*}{ PLGF } & Forward & GTTCAGCCCATCCTGTGTCT & \multirow[t]{2}{*}{$163 \mathrm{bp}$} \\
\hline & Reverse & AACGTGCTGAGAGAACGTCA & \\
\hline \multirow[t]{2}{*}{ sFLTI } & Forward & GGCTGTTTTCTCTCGGATCTC & \multirow[t]{2}{*}{$158 \mathrm{bp}$} \\
\hline & Reverse & САTСTCСTCCGAGCCTGAAAG & \\
\hline \multirow[t]{2}{*}{ VEGF } & Forward & GTC CCT CTT GGA ATT GGAT & \multirow[t]{2}{*}{$114 \mathrm{bp}$} \\
\hline & Reverse & TGTATGTGGGTGGGTGTGTC & \\
\hline \multirow[t]{2}{*}{$18 \mathrm{~S}$} & Forward & ACGGACCAGAGCGAAAGCAT & \multirow[t]{2}{*}{$145 \mathrm{bp}$} \\
\hline & Reverse & GCGGGTCATGGGAATAACG & \\
\hline
\end{tabular}


Table 2 VEGF family and demographic features

\begin{tabular}{|c|c|c|c|c|c|}
\hline \multirow[t]{2}{*}{ Variable } & \multirow{2}{*}{$\begin{array}{l}\text { Total patients } \\
(\mathrm{N}=40) \text {, n (\%) }\end{array}$} & \multicolumn{4}{|c|}{ Patients by study group, $\mathbf{n}(\%)$} \\
\hline & & PE & PE and UCAA & UCAA & Normal \\
\hline \multicolumn{6}{|l|}{ Newborn gender } \\
\hline Male & $20(50)$ & $6(15)$ & $5(12.5)$ & $4(10)$ & $5(12.5)$ \\
\hline Female & $20(50)$ & $4(10)$ & $5(12.5)$ & $6(15)$ & $5(12.5)$ \\
\hline \multicolumn{6}{|l|}{ Twins } \\
\hline Twin pregnancy & $0(0)$ & $0(0)$ & $0(0)$ & $0(0)$ & $0(0)$ \\
\hline Singleton pregnancy & $40(100)$ & $10(25)$ & $10(25)$ & $10(25)$ & $10(25)$ \\
\hline \multicolumn{6}{|l|}{ Parity } \\
\hline 3 or more children & $9(22.5)$ & $0(0)$ & $5(12.5)$ & $\mathrm{I}(2.5)$ & $3(7.5)$ \\
\hline 2 children & $15(37.5)$ & $2(5)$ & $3(7.5)$ & $5(12.5)$ & $5(12.5)$ \\
\hline I child & $16(40)$ & $8(20)$ & $2(5)$ & $4(10)$ & $2(5)$ \\
\hline \multicolumn{6}{|c|}{ Gestational age (weeks) } \\
\hline Preterm $<37$ & $15(37.5)$ & $7(17.5)$ & $8(20)$ & $0(0)$ & $0(0)$ \\
\hline Term 37-40 & $25(62.5)$ & $3(7.5)$ & $2(5)$ & $10(25)$ & $10(25)$ \\
\hline Posterm $>40$ & $0(0)$ & $0(0)$ & $0(0)$ & $0(0)$ & $0(0)$ \\
\hline \multicolumn{6}{|c|}{ Maternal age (years) } \\
\hline$<18$ & $0(0)$ & $0(0)$ & $0(0)$ & $0(0)$ & $0(0)$ \\
\hline $18-35$ & $30(75)$ & $6(15)$ & $8(20)$ & $8(20)$ & $8(20)$ \\
\hline$>35$ & $10(25)$ & $4(10)$ & $2(5)$ & $2(5)$ & $2(5)$ \\
\hline \multicolumn{6}{|c|}{ Paternal age (years) } \\
\hline$<18$ & $0(0)$ & $0(0)$ & $0(0)$ & $0(0)$ & $0(0)$ \\
\hline $18-40$ & $28(70)$ & $7(17.5)$ & $7(\mid 7.5)$ & $7(17.5)$ & $7(17.5)$ \\
\hline $4 I-55$ & $7(17.5)$ & $2(5)$ & $\mathrm{I}(2.5)$ & $3(7.5)$ & $\mathrm{I}(2.5)$ \\
\hline$>55$ & $0(0)$ & $0(0)$ & $0(0)$ & $0(0)$ & $0(0)$ \\
\hline Without data & $5(12.5)$ & $\mathrm{I}(2.5)$ & $2(5)$ & $0(0)$ & $2(5)$ \\
\hline \multicolumn{6}{|l|}{ Paternity } \\
\hline Primipaternity & $27(67.5)$ & $10(25)$ & $3(7.5)$ & $9(22.5)$ & $5(12.5)$ \\
\hline No primipaternity & $13(32.5)$ & $0(0)$ & $7(17.5)$ & $\mathrm{I}(2.5)$ & $5(12.5)$ \\
\hline \multicolumn{6}{|c|}{ Maternal weight gain (kg) } \\
\hline$<9$ & $14(35)$ & $3(7.5)$ & $4(10)$ & $3(7.5)$ & $4(10)$ \\
\hline $9-12$ & $8(20)$ & $2(5)$ & $2(5)$ & $2(5)$ & $2(5)$ \\
\hline$>12$ & $18(45)$ & $5(I 2.5)$ & $4(10)$ & $5(12.5)$ & $4(10)$ \\
\hline
\end{tabular}

Abbreviations: PE, preeclampsia; UCAA, umbilical cord anatomical abnormalities.

which the whole length was measured belongs to a previous project in which length was the main outcome.

\section{Immunohistochemistry}

Immunohistochemical analysis demonstrated highly variable activity among VEGF family members and among placental cells. Protein expression was analyzed within any kind of cell: syncytiotrophoblast, extravillous trophoblast, cytotrophoblast, chorionic plate's stromal cells, endothelium of chorionic and villous vessels, and smooth muscle of chorionic vessels, amnion, and decidua.

VEGF-A exhibits scarce positivity in the placental disc. The main activity was seen in the smooth muscle of chorionic vessels, even though the intensity was weak, and they were few cells. Stromal chorionic cells also exhibited weak expression. Few cases showed endothelial positivity (Figure 1). The amnion expression was smaller in the HDP context $(P=0.02$; $\mathrm{OR}=0.12 ; \mathrm{CI}=0.02-0.63)$. Statistical analysis showed no differences between other groups, nor in the anatomical UC alteration context.

VEGF-A immunohistochemistry was also carried out in the UC, where it was expressed, as well. Its expression was strong (score 2) in one-third of cases in the smooth muscle of the umbilical vessels; it was also positive in arterial and venous endothelial cells, stromal cells, and the amnion (Figure 2). Statistical analysis showed a difference upon 
Table 3 VEGF family and conditions of the mother and newborns related to each group of study

\begin{tabular}{|c|c|c|c|c|c|}
\hline \multirow[t]{2}{*}{ Maternal diseases } & \multirow{2}{*}{$\begin{array}{l}\text { Total patients } \\
(\mathrm{N}=40) \text {, n (\%) }\end{array}$} & \multicolumn{4}{|c|}{ Patients by study group, n (\%) } \\
\hline & & PE & PE and UCAA & UCAA & Normal \\
\hline \multicolumn{6}{|l|}{ Clinical condition } \\
\hline Endocrinological diseases & $4(10)$ & $2(5)$ & $0(0)$ & $2(5)$ & $0(0)$ \\
\hline Chronic hypertension & $8(20)$ & $6(15)$ & $2(5)$ & $0(0)$ & $0(0)$ \\
\hline Overweight/obesity & $3(7.5)$ & I (2.5) & $\mathrm{I}(2.5)$ & I (2.5) & $0(0)$ \\
\hline Migraine & $5(12.5)$ & $0(0)$ & $2(5)$ & $2(5)$ & I (2.5) \\
\hline Thyroid cancer or history of thyroid cancer & $2(5)$ & I (2.5) & $0(0)$ & I (2.5) & $0(0)$ \\
\hline Asthma/rhinitis & I (2.5) & $0(0)$ & I (2.5) & $0(0)$ & $0(0)$ \\
\hline Without maternal diseases & $18(45)$ & $2(5)$ & $3(7.5)$ & $4(10)$ & $9(22.5)$ \\
\hline \multicolumn{6}{|l|}{ Maternal complications of gestation } \\
\hline HDP & $20(50)$ & $10(25)$ & $10(25)$ & $0(0)$ & $0(0)$ \\
\hline Gestational diabetes & $3(7.5)$ & $2(5)$ & $\mathrm{I}(2.5)$ & $0(0)$ & $0(0)$ \\
\hline Premature rupture of membranes & I (2.5) & $0(0)$ & $0(0)$ & $0(0)$ & I (2.5) \\
\hline Urinary tract infection & $3(7.5)$ & $0(0)$ & $0(0)$ & $2(5)$ & $\mathrm{I}(2.5)$ \\
\hline Without gestacional complication & $13(32.5)$ & $0(0)$ & $0(0)$ & $6(15)$ & $7(17.5)$ \\
\hline \multicolumn{6}{|l|}{ Neonatal complications } \\
\hline Hyperbilirubinemia & $8(20)$ & $4(10)$ & $4(10)$ & $0(0)$ & $0(0)$ \\
\hline Fetal respiratory distress & $7(17.5)$ & $3(7.5)$ & $4(10)$ & $0(0)$ & $0(0)$ \\
\hline Asymptomatic hypoglycemia & $2(5)$ & $0(0)$ & $2(5)$ & $0(0)$ & $0(0)$ \\
\hline Congenital malformations & $\mathrm{I}(2.5)$ & I (2.5) & $0(0)$ & $0(0)$ & $0(0)$ \\
\hline Intrauterine growth restriction & $3(7.5)$ & $2(5)$ & I (2.5) & $0(0)$ & $0(0)$ \\
\hline Stillbirth & $0(0)$ & $0(0)$ & $0(0)$ & $0(0)$ & $0(0)$ \\
\hline Without neonatal complication & $22(55)$ & $3(7.5)$ & $\mathrm{I}(2.5)$ & $9(22.5)$ & $9(22.5)$ \\
\hline
\end{tabular}

Abbreviations: HDP, hypertensive disorders of pregnancy; PE, preeclampsia; UCAA, umbilical cord anatomical abnormalities.

comparing HDP cords with the normal group, smooth muscle cells of the umbilical vessels, where they lack VEGF-A expression in HDP $(P=0.03$; OR=3.45; $\mathrm{CI}=1.21-9.77)$. Also in the amnion, the expression was smaller in the HDP context $(P=0.04 ; \mathrm{OR}=2.85 ; \mathrm{CI}=1.13-7.15)$. In comparing anatomical UC alteration groups, there were no statistically significant differences.

On the contrary, VEGF-R1, was diffusely and strongly expressed in the syncytiotrophoblast, extravillous trophoblast, and decidua; a little less positivity was seen in the endothelium of chorionic and villous vessels, chorionic stromal cells, and the amnion (Figure 3 ). There were no statistically significant differences either in HDP or in anatomical abnormalities of the UC.

In the villous tree, PLGF was expressed widely in most cells (Figure 4A-D). In the extravillous trophoblast, the expression was strong (Figure 4A and B) and in the decidua, the expression was weak but constant - as constant as in the syncytiotrophoblast. An absent or weak PLGF expression in the syncytiotrophoblast is related to higher risk of HDP $(P=0.07 ; \mathrm{OR}=2.51 ; \mathrm{CI}=1.01-6.19)$. Multinucleated extravillous trophoblast was present in identical proportions between HDP and non-HDP groups, but in the HDP context, there was no PLGF $(P=0.02)$ expression. Stromal cells in the chorionic plate had constant expression, and this expression appears to be protective factor for $\operatorname{HDP}(P=0.04$; $\mathrm{OR}=0.17 ; \mathrm{CI}=0.03-0.86)$. Endothelial cells in villous capillaries and in stem villous had frequent expression with no link to HDP. Absence of PLGF expression was found to be protective for risk of UCAA in chorionic stromal cells ( $P=0.01 ; \mathrm{OR}=0.12 ; \mathrm{CI}=0.02-0.63)$, villous endothelium $(P=0.03 ; \mathrm{OR}=0.22 ; \mathrm{CI}=0.08-0.57)$, and endothelium in stem villi $(P=0.01 ; \mathrm{OR}=0.2 ; \mathrm{CI}=0.06-0.69)$; the same association was found with null or poor expression in basal trophoblast (beneath the decidua and insulation trophoblast) $(P=0.06$; $\mathrm{OR}=0.24 ; \mathrm{CI}=0.06-0.59$ ).

In the UC, most cells were positive, strong, and diffuse in the endothelium and in the amniotic epithelium (Figure 4C and D) and weak or absent in stromal and smooth muscle cells. We found a statistically significant difference in the expression of PLGF in venous endothelium; scant or absent expression signified higher risk for HDP 
Table 4 Umbilical cord anatomical abnormalities

\begin{tabular}{|c|c|}
\hline Coiling number & n (\%) \\
\hline Hypocoiled & $2(5)$ \\
\hline Hypercoiled & $3(7.5)$ \\
\hline Normal coiled $(0.07-0.3)$ & $35(87.5)$ \\
\hline \multicolumn{2}{|l|}{ Coiling direction } \\
\hline Dextro & $5(12.5)$ \\
\hline Bidirectional & $2(5)$ \\
\hline None & $0(0)$ \\
\hline Levo & $33(82.5)$ \\
\hline \multicolumn{2}{|l|}{ Insertion } \\
\hline Marginal insertion & $4(10)$ \\
\hline Velamentous insertion & $0(0)$ \\
\hline Paramarginal insertion & $0(0)$ \\
\hline Normal insertion & $36(90)$ \\
\hline \multicolumn{2}{|l|}{ Entanglements } \\
\hline Tight entanglements & $\mathrm{I}(2.5)$ \\
\hline Without & $39(97.5)$ \\
\hline \multicolumn{2}{|l|}{ Length } \\
\hline Long & $4(10)$ \\
\hline Short & $2(5)$ \\
\hline Without data & $17(42.5)$ \\
\hline Normal length & $17(42.5)$ \\
\hline \multicolumn{2}{|l|}{ Knots } \\
\hline True knot & I (2.5) \\
\hline True knot + bidirectional & I (2.5) \\
\hline Without knot & $38(95)$ \\
\hline \multicolumn{2}{|l|}{ Vessels } \\
\hline Two vessels (single umbilical artery) & $0(0)$ \\
\hline Three vessels & $40(100)$ \\
\hline
\end{tabular}

$(P=0.05 ; \mathrm{OR}=3.85 ; \mathrm{CI}=1.12-13.25)$. Absence of PLGF expression in smooth muscle cells is linked to $\operatorname{HDP}(P=0$; $\mathrm{OR}=19 ; \mathrm{CI}=4.02-89.61$ ).

MMP1 was positive and very specific in the trophoblast beneath the basal plate $20 \times$ (Figure 5A). The expression was frequent but weak in the smooth muscle of chorionic vessels and in chorionic stromal cells (Figure 5B) and highly variable in the decidua, extravillous trophoblast, and endothelium. Statistical analysis showed greater risk for HDP in the face of expression in the villous endothelium $(P=0.07 ; \mathrm{OR}=3.05 ; \mathrm{CI}=1.03-9.02)$, as was also the case in the chorionic endothelium $(P=0.01 ; \mathrm{OR}=6.85 ; \mathrm{CI}=1.41-33.3)$. Low MMP1 expression in the villous endothelium appears to be a protective agent for the UCAA $(P=0.07$; OR $=0.32$; $\mathrm{CI}=0.11-0.96)$. In the UC, most cells were negative; only a few amniotic cells showed positivity and staining was apical in the UC periphery.

Significant values are shown in Figure 6.

\section{qRT-PCR}

The amount of mRNA for each gene was normalized to $18 S$; the control was taken from the mean of controls. The fold change of genes is shown in Figure 7.

Expression of mRNA through $\Delta \Delta \mathrm{Ct}$ is shown in Figure 7A. In line with expectations, sFLT1' values were observed to be higher in HDP. In this group, PLGF and VEGF-A showed a trend toward lower values of expression, as expected (Figure 7B).

The UCAA group was unexpectedly different; sFLT1 and VEGF-A expression was consistently lower than in other groups (Figure 7). The Kruskal-Wallis test revealed a significant difference $(P=0000.1)$ when comparing the UCAA group for sFLT1 expression (Figure 8); said comparison was substantial between the UCAA group and the normal group and between the UCAA group and the HDP group.

The control group exhibited discreet variability and more homogeneous values.

The clinical sFlt-1:PLGF ratio was reproduced in the placental microenvironment through the mRNA study. Soluble fms-like tyrosine kinase 1 to placental growth factor ratio did not reveal expected results due to the fact that expression levels were similar among groups (with and without PE).

\section{Discussion}

\section{Clinical results}

PE contributes to perinatal and maternal morbidity and mortality and persists as a major obstetric concern; ${ }^{1-3,12}$ it is also a neonatal risk $^{10}$ and a future risk for both mother and newborn. ${ }^{3,6-9,11}$ Advances in some molecular alterations related to the VEGF family in $\mathrm{PE}^{30}$ currently have clinical applications, ${ }^{25}$ including as predictors of maternal outcomes in the short term. On the other hand, UC abnormalities are well recognized as risks for the fetus and newborns; ${ }^{31,32}$ the association between UC alterations and $\mathrm{PE}$ has also been established. ${ }^{15-17}$ This relation should guide neonatologists to be prepared for complications derived from both PE and UC abnormalities.

In this study, our chosen cohort with hypertension and UCAA developed maternal and newborn complications, with an expected high rate of prematurity (37.5\%). Primipaternity was also more frequent than in the consecutive series in the same population $(21.4 \%) ;{ }^{33}$ this value could be attributable to its association with PE. ${ }^{34}$ Maternal age $\geq 30$ years has been recognized as a risk factor for $\mathrm{PE} ;^{2}$ in our population of mothers $\geq 30$ years, 14 women developed HDP (70\%), which statistically corroborated a higher expected risk $(\mathrm{OR}=5.44)$.

Maternal weight was definitely abnormal because only $20 \%$ of expectant mothers gained between 9 and $12 \mathrm{~kg}$. 

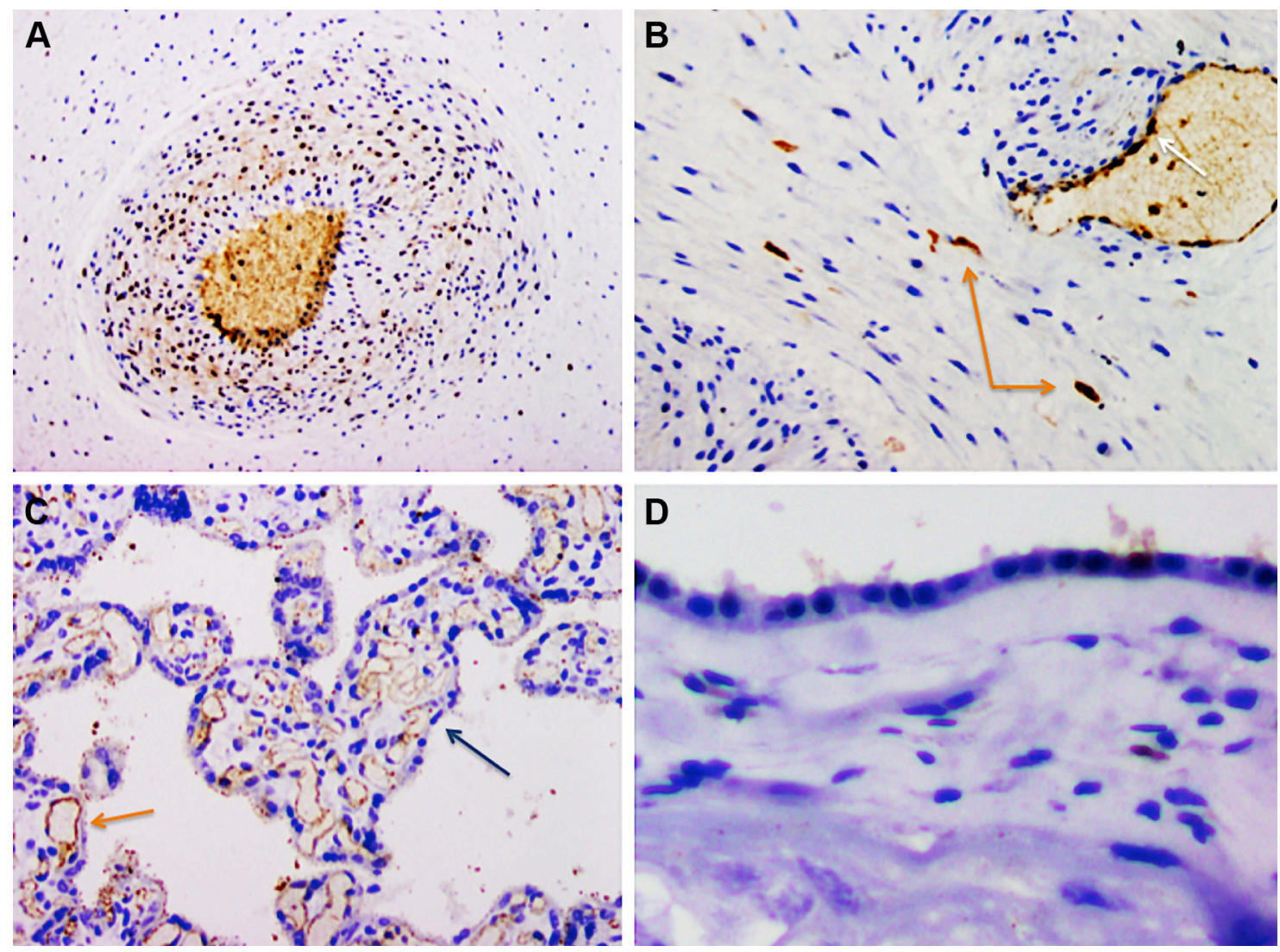

Figure I VEGF-A. Representative immunohistochemistry staining for VEGF-A in the placental disc. Positive expression demonstrated for smooth muscle of chorionic vessels, 10× (A), stromal chorionic cells, 20× (orange arrows), with positive internal control in chorionic endothelium (white arrow), and villous endothelial positivity (B), $20 \times$ (orange arrow), with negative internal control in syncytiotrophoblast (blue arrow) (C). Amnion negativity is shown 20× (D).

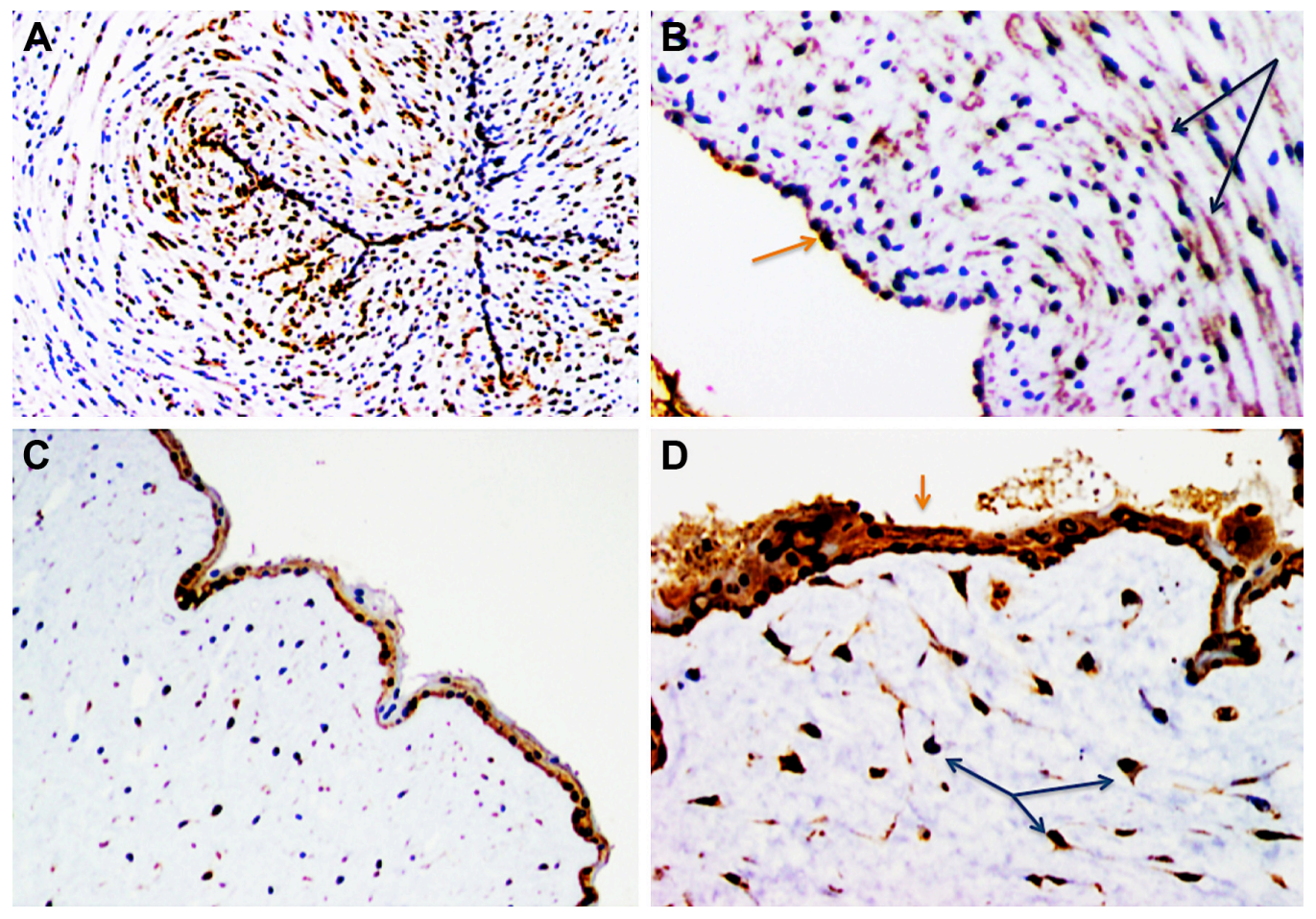

Figure 2 VEGF-A. Representative immunohistochemistry staining for VEGF-A in the umbilical cord.

Note: Positive expression demonstrated for smooth muscle of artery $4 \times(\mathbf{A})$, smooth muscle of artery (blue arrows) and endothelium 10× (orange arrow) (B), amnion (orange arrows) $10 \times$ and stromal cells (blue arrows) $20 \times(\mathbf{C}$ and $\mathbf{D})$. 


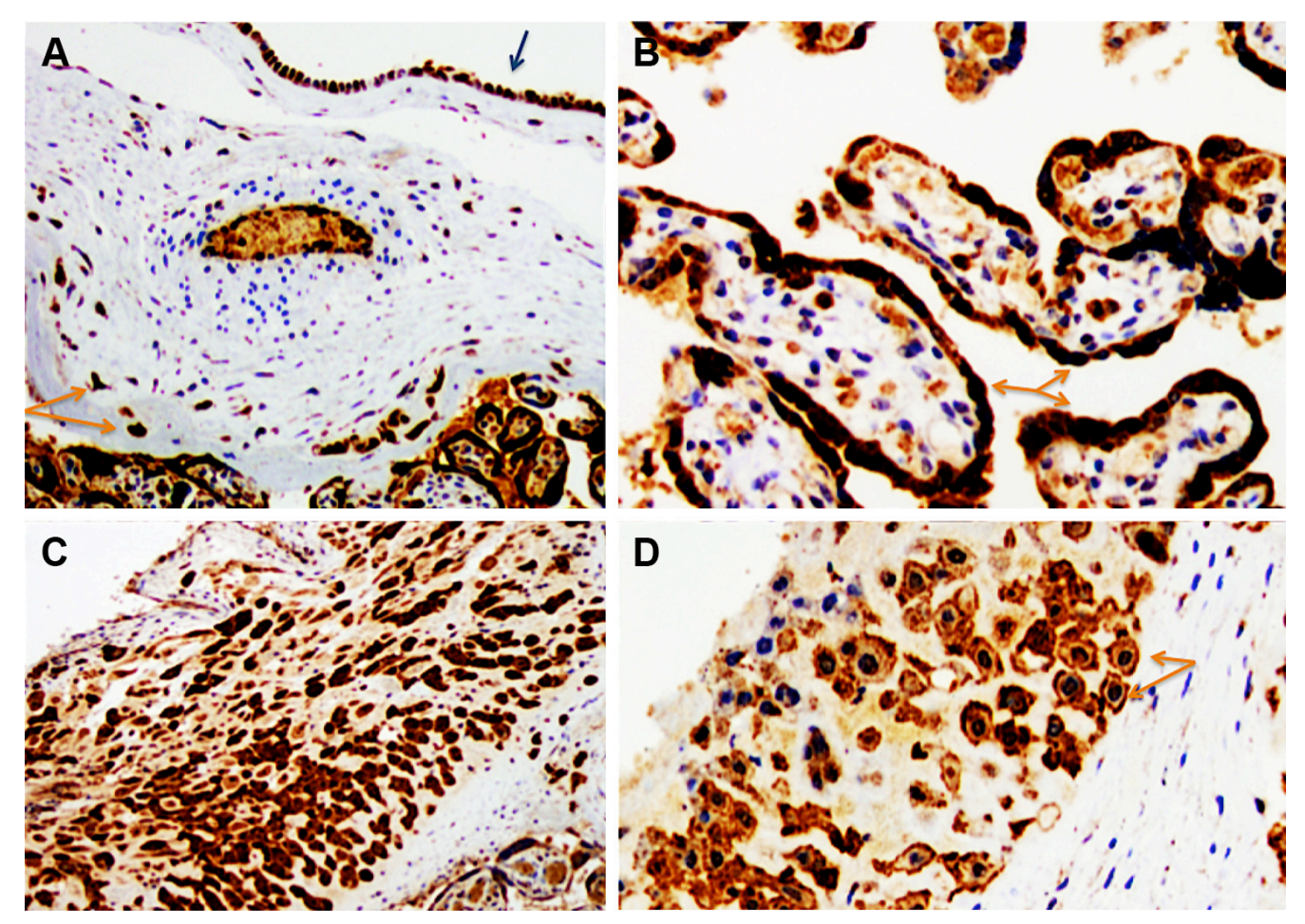

Figure 3 VEGF-RI. Representative immunohistochemistry staining for VEGF-RI in the placental disc.

Notes: Positive diffuse and strong expression demonstrated in syncytiotrophoblast $20 \times($ B), extravillous trophoblast $4 \times($ C), and decidua $20 \times($ D). Chorionic plate is highlighted in (A) 10×, where trophoblast (orange arrows) and amnion (blue arrow) are prominent. Negative internal controls are seen in $\mathbf{A}$ and $\mathbf{D}$ (blue cells).

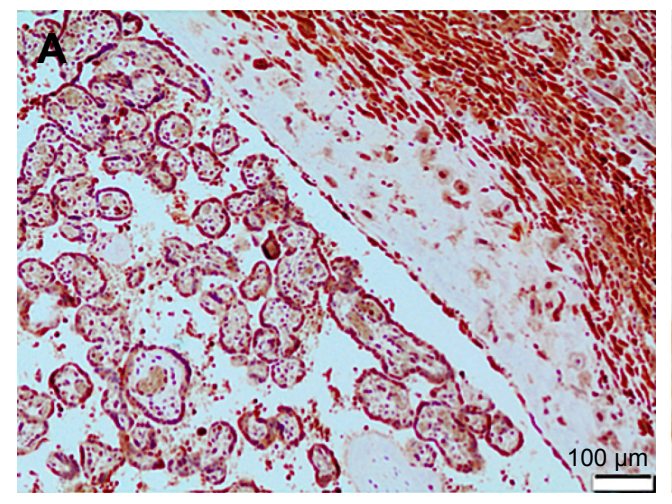

C
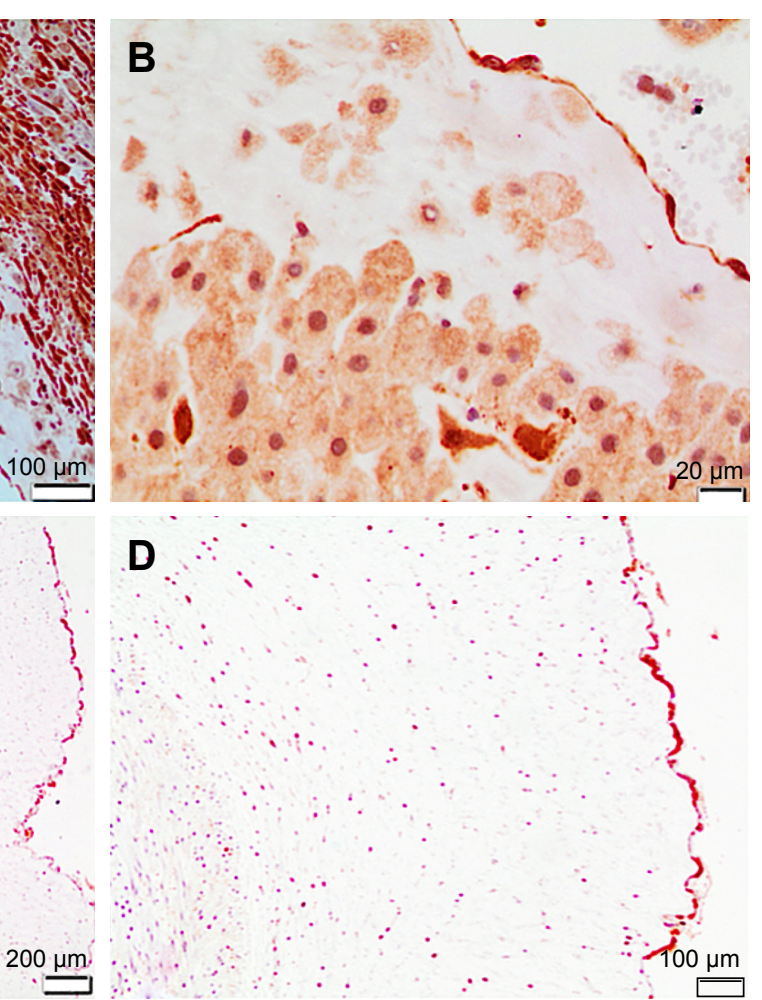

D.

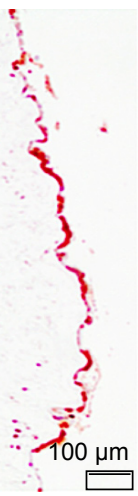

Figure 4 PLGF. Representative immunohistochemistry staining for PLGF.

Notes: (A) Diffuse and strong positivity is seen in extravillous trophoblast, basal trophoblast, and syncytiotrophoblast. In (B) strong expression of this kind of trophoblast contrasts with weak expression in decidua. In $\mathbf{C}$ and $\mathbf{D}$, umbilical cord shows strong and diffuse expression in the endothelium and the amniotic epithelium, even though it is present in smooth muscle cells, endothelium, and stromal cells. 

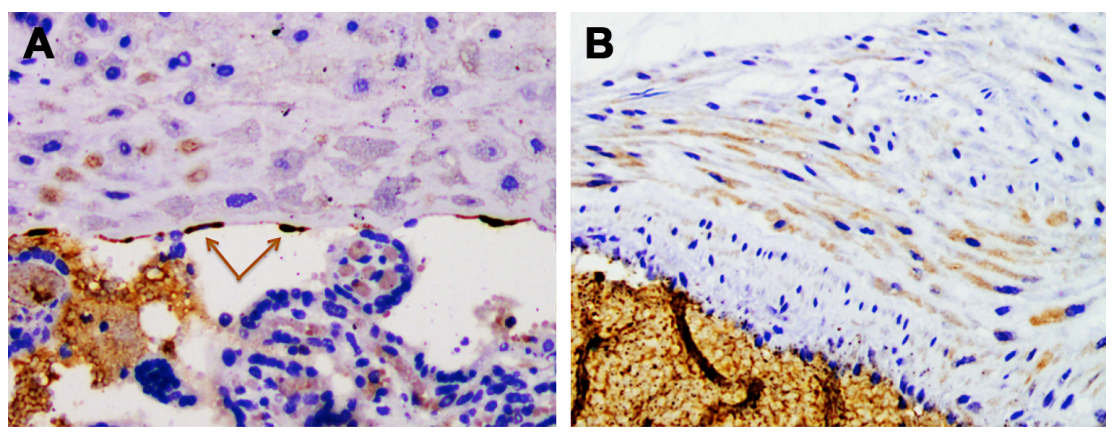

Figure 5 MMPI. Representative immunohistochemistry staining for MMPI in the placental disc.

Notes: Positive expression demonstrated in trophoblast behind the basal plate $20 \times(\mathbf{A})$ (arrows) and smooth muscle of chorionic vessels $20 \times(B)$. Negative internal controls are shown (blue cells).

Some mothers gained $<9 \mathrm{~kg}(35 \%)$ and $45 \%$ gained $>12 \mathrm{~kg}$; maternal weight does influence epigenetic regulation of many genes, including IGF2/H19 and CDKN1C, which are involved in fetus and UC growth. ${ }^{35,36}$

Despite the knowledge that half the maternal cohort presented HDP, some diseases were observed in the other study groups: only $45 \%$ were completely healthy before gestation, and only $32.5 \%$ had no gestational complications. On the other hand, $55 \%$ of newborns exhibited no abnormalities during hospitalization. Beyond the major factor of our chosen group (HDP context), the complexity of our hospital added another selection bias, because pregnant women

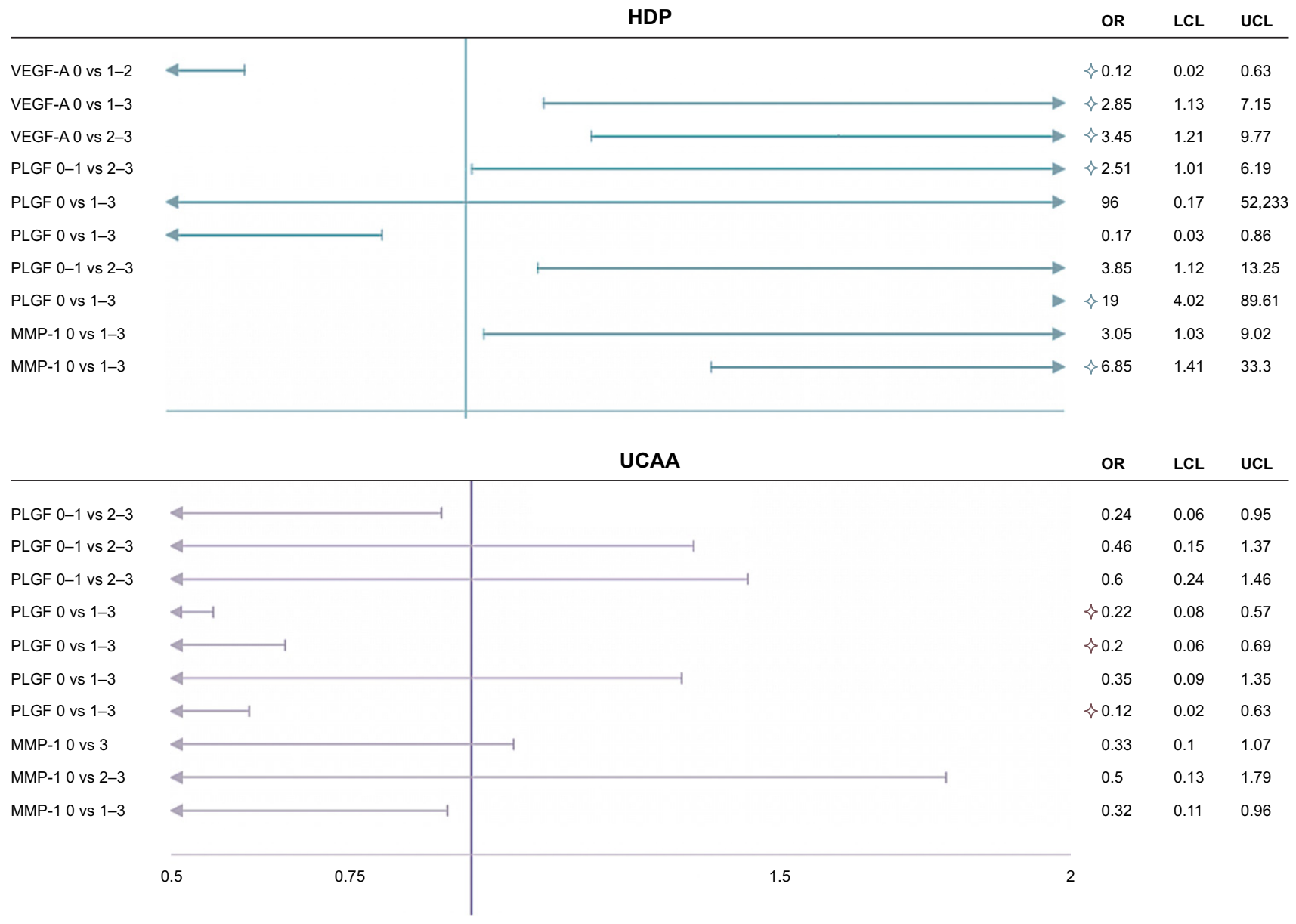

Figure 6 Immunohistochemistry summary.

Notes: Galbraith's graphic shows the compilation of the most representative results. LCL corresponds to minor $\mathrm{Cl}$ and $\mathrm{UCL}$ corresponds to major $\mathrm{Cl}$. Abbreviations: HDP, hypertensive disorders of pregnancy; UCAA, umbilical cord anatomical alterations. 
A
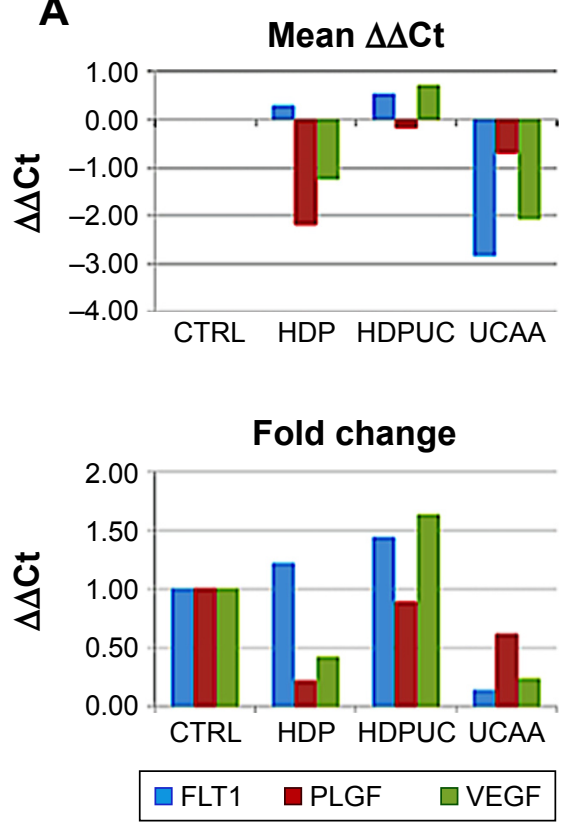

Figure 7 mRNA expression summary.

Notes: Bar graphs (A) and box and whisker plots (B) show differences among groups: HDP, UCAA, HDPUC, and normal gestations (CTRL). The UCAA group was unexpectedly different; sFLTI and VEGF-A expression was consistently lower than other groups.

Abbreviations: CTRL, control; HDP, hypertensive disorders of pregnancy; HDPUC, HDP plus UCAA; UC, umbilical cord; UCAA, UC anatomical abnormalities.

admitted usually have increased risk for complications, as do their newborns.

The UCAA included in the groups involved insertion, coiling, length, true knots, and entanglements. All of these alterations have been described as risk factors for fetus and newborns and are linked to neurological delay; neurological abnormalities (degenerative cerebral changes, white matter damage, altered imaging studies, and cerebral palsy) have been explained through germinal matrix or intraventricular hemorrhage, gliosis, or necrosis of the white matter and neuronal necrosis..$^{19,37-39}$ The UCAA have been described as being more frequently associated with HDP. ${ }^{15}$ We found more abnormal length that expected: for short cords $5 \%(2 \%-4 \%)$, and for long cords $10 \%(4 \%-6 \%)$, similar to what has been observed in another series in the same population and in the population with malformations. ${ }^{40}$

\section{Protein expression}

The VEGF family is linked to the known molecular distorted microenvironment in the preeclamptic placenta. ${ }^{24-26} \mathrm{We}$ hypothesize that VEGF members could also be involved in $\mathrm{UC}$ anatomical alterations as they are in PE, because of the latter's common vascular origin; they may reflect defects originated from poor blood supply in early placentation and in UC development.
Flt1

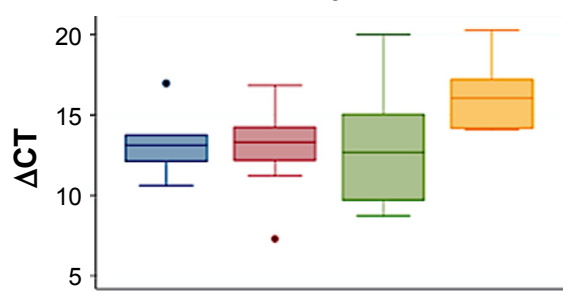

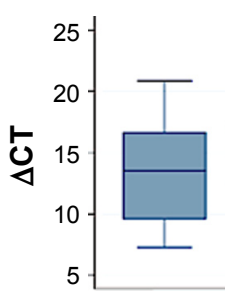

PLGF

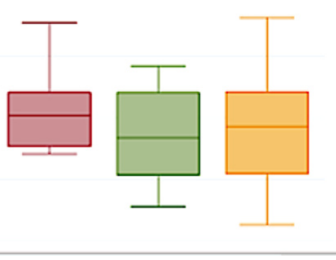

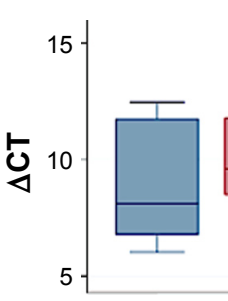

VEGF

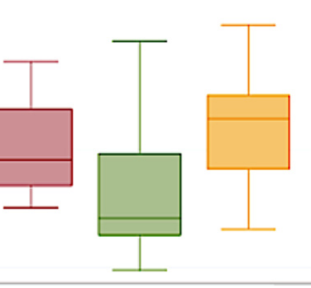

$\square$ Controls $\square$ HDPUC $\square$ HDP $\square$ UCAA

Figure 8 mRNA expression summary.

Notes: mRNA expression summary. Kruskal-Wallis test revealed significant differences upon comparing UCAA group in sFlt I expression. In the $y$-axis, $\triangle \mathrm{CT}$. Abbreviations: HDP, hypertensive disorders of pregnancy; HDPUC, HDP plus UCAA; UC, umbilical cord; UCAA, umbilical cord anatomical abnormalities. 
In a subsequent step, we tested members of the VEGF family, first, for protein expression levels (intensity and extension) in different kinds of cells in the placental disc and these were then compared with those in the UC.

- VEGF-A: we described its many functions in endothelial cells: as a promoter of angiogenesis, as an inductor of growth in vascular endothelial cells, ${ }^{41}$ and as a reducer of apoptosis. ${ }^{42}$ With high affinity, VEGF-A binds to two tyrosine kinases receptors expressed on vascular endothelial cells, R1 and R2. ${ }^{42}$ We saw little protein expression in the placenta disc, even less so when compared to R1 expression, which was strong. Protein expression was also very discrete in UC cells (arterial and venous endothelial cells, smooth muscle cells, stromal cells, and the amnion). UC amnion expression was significantly lower in the HDP context. In the UC smooth muscle, the risk for HDP presence was higher. Loss of its expression in the amnion of the chorionic plate appears to be a protective factor.

- VEGF-R1 (FLT1): this protein is predominantly expressed in the placenta, the heart, and the lungs. Its role is not yet completely understood; however, it is possibly important in regulating VEGF-dependent angiogenesis under pathological conditions. ${ }^{42}$ We observed significant and diffuse expression; very strong in the placental disc. We did not observe differences either in the HDP cases or in the anatomical abnormalities of the UC. It should be kept in mind that the sizeable amount of this receptor in every kind of cell in the placenta and in the UC could be related to the role of its soluble form in PE.

- PLGF: this is the placenta analog of VEGF; it has proinflammatory and angiogenic properties. ${ }^{43}$ In animal models, mRNA PLGF level has decreased in both serum and placenta in intrauterine growth restriction (IUGR). ${ }^{44}$ Through immunohistochemistry, PLGF has been reported expressed in syncytiotrophoblast and endothelial cells of the fetal capillaries in human placentas; ${ }^{45}$ however, we found its expression in more cells: extravillous trophoblast, decidua, chorionic stromal cells, basal trophoblast, in addition to syncytiotrophoblast and endothelial cells of the fetal capillaries. We also found expression in the UC cells (described earlier). Comparing normal and abnormal placentas, PLGF has been reported to be normal in serum and as increased in placental tissue in cases of placental dysfunction (IUGR and PE); ${ }^{44}$ with Elisa, others have reported it as more significantly decreased in preeclamptic placentas than in normotensive ones. ${ }^{45}$ Our study found that the absence of PLGF expression in stromal cells could be a protector for HDP; on the contrary, it appears to be a risk factor when it is absent or scant in the syncytiotrophoblast and in the UC (endothelium and smooth muscle cells). The absence of its expression also appears to be a protector for UCAA in accordance with our results. To our knowledge, there are no other studies describing PLGF associated with UCAA.

- MMP1: we included MMP1, searching for any activity in anchoring villi, due to increased VEGF expression of the metalloproteinase in the UC41 and to the fact of their having been involved with invasive trophoblast, in early placental development, ${ }^{46}$ and also probably in PE. ${ }^{47}$ This expression was clearly predominant in the basal plate, where its expression had a higher punctuation. This corresponded to the theoretically expected location and was, at the same time, very specific for this kind of trophoblast. Statistical analysis showed a greater risk for HDP in light of the lack of expression in both endothelium: villous and chorionic. But contrary to expectations, trophoblast expression was not different in the HDP context in this series. The absence of its expression in villous endothelium was also considered as being a protective factor for UCAA.

\section{RNA expression}

As far as we know, to date, there are no studies that deal with sFLT1 expression in placenta environment. mRNA expression values of sFLT1 were higher in HDP and lower in PLGF and VEGF-A, compared to normal gestations. Although no statistically significant differences were found, a tendency could be observed.

The UCAA group behavior was surprisingly different than that in other groups exhibiting mRNA expression of sFLT1 and VEGF-A, being consistently lower than for other groups and with statistical significance for SFLT1; this comparison remained valid against both the normal group and the HDP group. Currently, there are no explanations for this observation: first, because sFLT1 had not been tested either in the UC or in the UCAA; second, because the UCAA did not have a proven molecular link to recognize it as a possible etiological factor. IGF2 and CDKN1C have been related to the length of the CU, exclusively. ${ }^{36}$ However, our study group included the other alterations of the CU: short and long length, dextro-rotatory (clockwise), hypercoiled cords (winding index greater than 0.3 ), hypocalized cords index of winding less than 0.07), and tangles, thick cords (diameter greater than $1.6 \mathrm{~cm}$ ). In addition, some cords exhibited more than one alteration. We can now hypothesize that the VEGF family is involved in UC anatomical features and in UC 
development; sFLT1 could also be proposed as a molecule associated with UCAA.

The sFlt-1:PlGF ratio is clinically described as abnormal in preeclamptic mothers. We attempted its reproduction in the placental microenvironment through the mRNA study. Placental results were not similar to those in clinical studies. The explanation could be related to PLGF decrease with labor duration; ${ }^{48}$ PLGF (both mRNA and protein) has also been observed as decreasing in labor samples. ${ }^{48}$ Most such studies have been carried out in maternal serum. ${ }^{25,49,50}$

The relation between mRNA and protein expression could not be performed because levels in protein expression were separated by each kind of cell; this level of discrimination by cells is not possible with mRNA measurements.

Our study reveals the need to further investigate the following questions related to normal UC development:

1. What molecular pathways are active in $\mathrm{UC}$ development?

2. Could these molecular pathways be altered by HDP?

3. If UCAA and HDP are linked, could they share the same etiology?

4. Do UCAA also begin in the blastocyst implantation process, as stated in HDP theories?

5. Due to the significant amount of VEGF-R1 in every kind of placental cells, what is its real role in placental functions?

6. Is the VEGF family a major factor in placenta and UC development?

\section{Conclusion}

The vascular origin of the UC and its abnormalities shown in HDP are still misunderstood. We observed abnormal VEGF family protein and mRNA expression in both the PE and the UCAA. Knowledge of molecular factors involved in placenta and UC origin could help in understanding the etiology of the UCAA and possibly its relation to HDP. Some VEGF family members appeared as candidates linked to UCAA.

Our hypothesis on the VEGF family as UCAA and HDP common links was at least partially validated by this study. This study provides the first approach related to vascular organs, vascular molecules, and vascular diseases in pregnancy.

\section{Human research statement}

This study was conducted in accordance with the ethical standards of all applicable national and institutional committees and the World Medical Association's Declaration of Helsinki.

\section{Acknowledgments}

We wish to thank the Fundacion Carolina de España, Pontificia Universidad Javeriana - Hospital Universitario San Ignacio in Bogota, and Vall d'Hebron Research Institute (VHIR), Universitat Autònoma de Barcelona, España for their indispensable support and participation in this study. We also extend our thanks to the parents who participated in this study and to Steven W Bayless for the English language text correction. This study constitutes part of the research project entitled, "Molecular alteration in vascular placental development", (ID PPTA 00008027) financed by the Pontificia Universidad Javeriana - Hospital Universitario San Ignacio in Bogota, Colombia, and the Vall d'Hebron Research Institute (VHIR), Universitat Autònoma de Barcelona, Spain.

\section{Disclosure}

None of the authors has any potential or actual interests relevant to the topics discussed in this manuscript. The authors report no conflicts of interest in this work.

\section{References}

1. US Preventive Services Task Force, Bibbins-Domingo K, Grossman DC, et al. Screening for preeclampsia: US preventive services task force recommendation statement. JAMA. 2017;317(16):1661-1667.

2. Bilano VL, Ota E, Ganchimeg T, Mori R, Souza JP. Risk factors of pre-eclampsia/eclampsia and its adverse outcomes in low- and middleincome countries: a WHO secondary analysis. PLoS One. 2014;9(3): e91198.

3. Foo L, Tay J, Lees CC, McEniery CM, Wilkinson IB. Hypertension in pregnancy: natural history and treatment options. Curr Hypertens Rep. 2015;17(5):36.

4. Shennan AH, Green M, Chappell LC. Maternal deaths in the UK: preeclampsia deaths are avoidable. Lancet. 2017;389(10069):582-584.

5. Steegers EA, von Dadelszen P, Duvekot JJ, Pijnenborg R. Pre-eclampsia. Lancet. 2010;376(9741):631-644.

6. Black MH, Zhou H, Sacks DA, et al. Hypertensive disorders first identified in pregnancy increase risk for incident prehypertension and hypertension in the year after delivery. J Hypertens. 2016;34(4):728-735.

7. Amaral LM, Cunningham MW, Cornelius DC, Lamarca B. Preeclampsia: long-term consequences for vascular health. Vasc Health Risk Manag. 2015;11:403-415.

8. Piccoli GB, Cabiddu G, Castellino S, et al. A best practice position statement on the role of the nephrologist in the prevention and follow-up of preeclampsia: the Italian study group on kidney and pregnancy. J Nephrol. 2017;30(3):307-317.

9. Lee G, Tubby J. Preeclampsia and the risk of cardiovascular disease later in life - A review of the evidence. Midwifery. 2015;31(12):1127-1134.

10. Kinney MV, Lawn JE, Howson CP, Belizan J. 15 Million preterm births annually: what has changed this year? Reprod Health. 2012;9(28):28.

11. Gumina DL, Su EJ, Ej S. Endothelial progenitor cells of the human placenta and fetoplacental circulation: a potential link to fetal, neonatal, and long-term health. Front Pediatr. 2017;5:41.

12. Wagnew M, Dessalegn M, Worku A, Nyagero J. Trends of preeclampsia/ eclampsia and maternal and neonatal outcomes among women delivering in addis ababa selected government hospitals, Ethiopia: a retrospective cross-sectional study. Pan Afr Med J. 2016;25(Suppl 2):12.

13. Perrone S, Santacroce A, Picardi A, Buonocore G. Fetal programming and early identification of newborns at high risk of free radical-mediated diseases. World J Clin Pediatr. 2016;5(2):172-181. 
14. Herzog EM, Eggink AJ, Reijnierse A, et al. Impact of early- and lateonset preeclampsia on features of placental and newborn vascular health. Placenta. 2017:49:72-79.

15. Olaya-C M, Salcedo-Betancourt J, Galvis SH, Ortiz AM, Gutierrez S, Bernal JE. Umbilical cord and preeclampsia. J Neonatal Perinatal Med. 2016;9(1):49-57.

16. Goynumer G, Ozdemir A, Wetherilt L, Durukan B, Yayla M. Umbilical cord thickness in the first and early second trimesters and perinatal outcome. J Perinat Med. 2008;36(6):523-526.

17. Ferguson VL, Dodson RB. Bioengineering aspects of the umbilical cord Eur J Obstet Gynecol Reprod Biol. 2009;144(Suppl 1):S108-S113.

18. Olaya-C MBJ. Umbilical cord abnormalities in fetal and neonatal pathology in Bogota. APM. 2014;20(1):22-27.

19. Redline RW. Correlation of placental pathology with perinatal brain injury. Surg Pathol Clin. 2013;6(1):153-180.

20. Roescher AM, Timmer A, Erwich JJ, Bos AF. Placental pathology, perinatal death, neonatal outcome, and neurological development: a systematic review. PLoS One. 2014;9(2):e89419.

21. Nasiell J, Papadogiannakis N, Löf E, Elofsson F, Hallberg B. Hypoxic ischemic encephalopathy in newborns linked to placental and umbilical cord abnormalities. J Matern Fetal Neonatal Med. 2016;29(5):721-726.

22. Binder NK, Evans J, Salamonsen LA, Gardner DK, Kaitu'u-Lino TJ, Hannan NJ. Placental growth factor is secreted by the human endometrium and has potential important functions during embryo development and implantation. PLoS One. 2016;11(10):e0163096.

23. Benton SJ, Mccowan LM, Heazell AE, et al. Placental growth factor as a marker of fetal growth restriction caused by placental dysfunction. Placenta. 2016;42:1-8.

24. Duhig KE, Chappell LC, Shennan AH. How placental growth factor detection might improve diagnosis and management of pre-eclampsia. Expert Rev Mol Diagn. 2014;14(4):403-406.

25. Zeisler H, Llurba E, Chantraine F, et al. Predictive value of the sFlt-1:PlGF ratio in women with suspected preeclampsia. $N$ Engl $J$ Med. 2016;374(1):13-22.

26. Sovio U, Gaccioli F, Cook E, Hund M, Charnock-Jones DS, Smith GC Prediction of preeclampsia using the soluble fms-like tyrosine kinase 1 to placental growth factor ratio: a prospective cohort study of unselected nulliparous women. Hypertension. 2017;69(4):731-738.

27. American College of Obstetricians and Gynecologists Task Force on Hypertension in Pregnancy. Hypertension in pregnancy. Report of the American College of Obstetricians and Gynecologists' Task Force on Hypertension in Pregnancy. Obstet Gynecol. 2013;122(5):1122-1131.

28. Kaplan C, editor. Normal values for placentas. Color Atlas of Gross Placental Pathology. New York: Springer; 2007:119-122.

29. Chang SD, Chao AS, Peng HH, et al. Analyses of placental gene expression in pregnancy-related hypertensive disorders. Taiwan J Obstet Gynecol. 2011;50(3):283-291.

30. Saha T, Halder M, Das A, Das SK. Role of nitric oxide, angiogenic growth factors and biochemical analysis in preeclampsia. Indian $J$ Biochem Biophys. 2013;50(5):462-466.

31. Collins JH, Collins CLCC. Silent Risk - Issues about the Human Umbilical Cord. Bloomington, IN: Xlibris; 2011.

32. Saleemuddin A, Tantbirojn P, Sirois K, et al. Obstetric and perinatal complications in placentas with fetal thrombotic vasculopathy. Pediatr Dev Pathol. 2010;13(6):459-464.
33. Olaya-C M, Salcedo J, Salazar A, Silva J, Bernal J. Anatomical pathology of the umbilical cord and its maternal and fetal clinical associations in 434 newborns. Pediatr Dev Pathol. 2018;21(5):467-474.

34. Robillard PY, Dekker G, Chaouat G, Hulsey TC, Saftlas A. Epidemiological studies on primipaternity and immunology in preeclampsia - a statement after twelve years of workshops. J Reprod Immunol. 2011;89(2):104-117.

35. Gicquel C, El-Osta A, Le Bouc Y. Epigenetic regulation and fetal programming. Best Pract Res Clin Endocrinol Metab. 2008;22(1):1-16.

36. Olaya-C M, Fritsch M, Bernal JE. Immunohistochemical protein expression profiling of growth- and apoptotic-related factors in relation to umbilical cord length. Early Hum Dev. 2015;91(5):291-297.

37. Grafe MR. The correlation of prenatal brain damage with placental pathology. J Neuropathol Exp Neurol. 1994;53(4):407-415.

38. Baergen RN, Malicki D, Behling C, Benirschke K. Morbidity, mortality, and placental pathology in excessively long umbilical cords: retrospective study. Pediatr Dev Pathol. 2001;4(2):144-153.

39. Redline RW, Wilson-Costello D, Borawski E, Fanaroff AA, Hack M. The relationship between placental and other perinatal risk factors for neurologic impairment in very low birth weight children. Pediatr Res. 2000;47(6):721-726.

40. Olaya-C M, Bernal JE. Clinical associations to abnormal umbilical cord length in Latin American newborns. J Neonatal Perinatal Med. 2015;8(3):251-256.

41. Ferrara N, Davis-Smyth T. The biology of vascular endothelial growth factor. Endocr Rev. 1997;18(1):4-25.

42. Andraweera PH, Dekker GA, Roberts CT. The vascular endothelial growth factor family in adverse pregnancy outcomes. Hum Reprod Update. 2012;18(4):436-457.

43. Vrachnis N, Kalampokas E, Sifakis S, et al. Placental growth factor (PlGF): a key to optimizing fetal growth. J Matern Fetal Neonatal Med. 2013;26(10):995-1002.

44. Li SW, Ling Y, Jin S, et al. Expression of soluble vascular endothelial growth factor receptor-1 and placental growth factor in fetal growth restriction cases and intervention effect of tetramethylpyrazine. Asian Pac J Trop Med. 2014;7(8):663-667.

45. Weel IC, Baergen RN, Romão-Veiga M, et al. Association between placental lesions, cytokines and angiogenic factors in pregnant women with preeclampsia. PLoS One. 2016;11(6):e0157584.

46. Aghababaei M, Perdu S, Irvine K, Beristain AG. A disintegrin and metalloproteinase 12 (ADAM12) localizes to invasive trophoblast, promotes cell invasion and directs column outgrowth in early placental development. Mol Hum Reprod. 2014;20(3):235-249.

47. Cohen M, Ribaux P, Epiney M, Irion O. Expression of metalloproteinases 1, 2, 7,9, and 12 in human cytotrophoblastic cells from normal and preeclamptic placentas. Neuro Endocrinol Lett. 2012;33(4):406-411.

48. Cindrova-Davies T, Yung HW, Johns J, et al. Oxidative stress, gene expression, and protein changes induced in the human placenta during labor. Am J Pathol. 2007;171(4):1168-1179.

49. Conti E, Zezza L, Ralli E, et al. Growth factors in preeclampsia: a vascular disease model. A failed vasodilation and angiogenic challenge from pregnancy onwards? Cytokine Growth Factor Rev. 2013;24(5):411-425.

50. Ehrlich L, Hoeller A, Golic M, et al. Increased placental sFlt-1 but unchanged PlGF expression in late-onset preeclampsia. Hypertens Pregnancy. 2017;36(2):175-185.
International Journal of Women's Health

\section{Publish your work in this journal}

The International Journal of Women's Health is an international, peerreviewed open-access journal publishing original research, reports, editorials, reviews and commentaries on all aspects of women's healthcare including gynecology, obstetrics, and breast cancer. The manuscript management system is completely online and includes

\section{Dovepress}

a very quick and fair peer-review system, which is all easy to use. Visit http://www.dovepress.com/testimonials.php to read real quotes from published authors. 